\title{
Elevated temperature transmission Kikuchi diffraction in the SEM
}

Fanta, Alice Bastos; Todeschini, Matteo; Burrows, Andrew; Jansen, Henri; Damsgaard, Christian Danvad; Alimadadi, Hossein; Wagner, Jakob Birkedal

Published in:

Materials Characterization

Link to article, DOI:

10.1016/j.matchar.2018.03.026

Publication date:

2018

Document Version

Peer reviewed version

Link back to DTU Orbit

Citation $(A P A)$ :

Fanta, A. B., Todeschini, M., Burrows, A., Jansen, H., Damsgaard, C. D., Alimadadi, H., \& Wagner, J. B. (2018). Elevated temperature transmission Kikuchi diffraction in the SEM. Materials Characterization, 139, 452-462. https://doi.org/10.1016/j.matchar.2018.03.026

\section{General rights}

Copyright and moral rights for the publications made accessible in the public portal are retained by the authors and/or other copyright owners and it is a condition of accessing publications that users recognise and abide by the legal requirements associated with these rights.

- Users may download and print one copy of any publication from the public portal for the purpose of private study or research.

- You may not further distribute the material or use it for any profit-making activity or commercial gain

- You may freely distribute the URL identifying the publication in the public portal 
Keywords

TKD, in-situ annealing, solid state dewetting, Au thin-film

\section{Abstract}

Transmission Kikuchi diffraction (TKD) facilitates automated orientation mapping of thin films in scanning electron microscopes (SEM). In this study TKD is applied for the first time to perform insitu annealing experiments on gold thin films deposited on a MEMS-based heating system. The very local heating associated with this system enables reliable TKD measurements at elevated temperatures without notable disturbance from infrared radiation. The dewetting of an Au thin film into $\mathrm{Au}$ nanoparticles upon heating is followed with orientation mapping in a temperature range between $20^{\circ} \mathrm{C}$ and $900^{\circ} \mathrm{C}$. The local thickness variation associated with the dewetting is observed qualitatively by observing the intensity of the transmitted beam, which decreases as the film thickness increases locally. The results of this study reveal that TKD is a well suited technique to study thin-film stability and solid state dewetting. Moreover, the outcome of this methodological study provides a baseline for further in-situ crystallographic studies of electron transparent samples in the SEM.

\section{Introduction}

Since transmission Kikuchi diffraction (TKD) was introduced by Keller and Geiss [1,2] in 2012, the technique has received increasing interest and has been applied to investigate several material systems [3-11] within a large range of fields [1,4-8,10,12-14]. Additionally, a considerable focus has been directed to further understanding and optimising the technique [9,11,14-20]; besides improvements related to the acquisition software, and some new hardware developments [21-23].

Several authors have discussed TKD in comparison to EBSD and orientation mapping in TEM $[12,24,25]$, pointing out its advantages and disadvantages. It is reasonable to see TKD as a complementary technique to both EBSD and TEM; however it is evident that the focus, up to now, has been concentrated on complementing EBSD with the additional spatial resolution of TKD [11,12,26-28]. It has been indicated previously that one disadvantage of TKD in comparison to EBSD lies in the requirement of having electron transparent samples, which leads to more demanding sample preparation [24]. Furthermore, the analysis of thinned samples or thin focused ion beam (FIB) lamellas prepared from bulk specimens limits the investigation area, which may not truly represent the bulk sample.

On the other hand, TKD provides opportunities to investigate electron transparent crystalline samples quantitatively in the SEM. Many samples, which were conventionally investigated only with the TEM, due to their resolution requirements or their small volume or thickness, can now also be investigated by TKD in the SEM. Considering that SEMs are more commonly accessible and relatively simpler to operate than TEMs, this perspective will most probably attract further attention and interest to the technique.

Solid state dewetting is a known phenomenon in which a continuous thin film will agglomerate at temperatures well below the film's melting temperature and form particles. The driving force for dewetting is the minimization of the total energy of surfaces and interfaces $[29,30]$. The dewetting 
process of gold is known to be divided in three main stages: (i) hole nucleation and grain growth; (ii) hole growth and "finger" formation and (iii) film break up into separate particles [31,32]. Solid state dewetting depends on several parameters such as initial film thickness, deposition method, substrate, annealing temperature, time and atmosphere [29,31,33]. Furthermore, it is known that grain growth, texture, grain boundaries and triple junctions play an important role on the dewetting process $[29,34,35]$.

While dewetting is associated with the disintegration of the film at elevated temperatures, which is detrimental for the performance of micro and nanodevices [36], it can also be employed as an effective tool for producing ordered nanoparticle arrays useful for various applications [30,37-40]. Both fields have received considerable research interest and the dewetting process has been comprehensively reviewed $[29,30,40,41]$ and widely investigated in the past decade. Within those investigations, electron microscopy was frequently applied to investigate the post-annealing film surface $[42,43]$, whilst some in-situ microscopy investigation have recently been carried out $[34,44-$ 46]. However, only a few of these studies investigated the effect of crystallographic orientation on the dewetting process $[31,35,46]$.

From the microstructural point of view, TKD is ideal to investigate solid state dewetting of thin films, as it combines an improved spatial resolution in comparison to EBSD, with the ability of investigating thin samples in an SEM. In the present work, this possibility is tested by means of performing in-situ annealing and dewetting of Au thin films deposited on a MEMS-based (Micro-Electro-MechanicalSystems) heating holder with TKD in an SEM, with a particular focus on the demonstration of the capabilities of TKD for such in-situ heating experiments. The perspective of the technique will be demonstrated with respect to the potential impact on the in-situ characterization of dynamic phenomena in low-dimensional or nanosized materials.

\section{Experimental details}

To perform the in-situ TKD annealing experiments thin gold films $(15 \mathrm{~nm})$ were deposited by electron beam evaporation using a Wordentec QCL 800 (Wordentec Limited Shebbear, UK) on MEMS-based heating chips (Wildfire, DENSsolutions, Delft, The Netherlands). The film was deposited with a deposition rate of $1 \AA / \mathrm{s}$, chamber pressure of $3 \times 10^{-6} \mathrm{mbar}$ and substrate temperature between $17^{\circ} \mathrm{C}$ and $20^{\circ} \mathrm{C}$. A quartz crystal microbalance $(\mathrm{QCM})$ was used to determine the film thickness. Figure 1(a) shows an SEM image of the heating chip, featuring several electron transparent windows of 5 $\mu \mathrm{m} \times 20 \mu \mathrm{m}$, with $20 \mathrm{~nm}$ thick amorphous silicon nitride membranes as support. Figure 1 (b) shows the investigated window in the centre of the chip and Fig. 1(c) a STEM bright field image of the investigated window covered with the Au film. This image was obtained with the ARGUS ${ }^{\mathrm{TM}}$ solid state detector positioned below the sample.
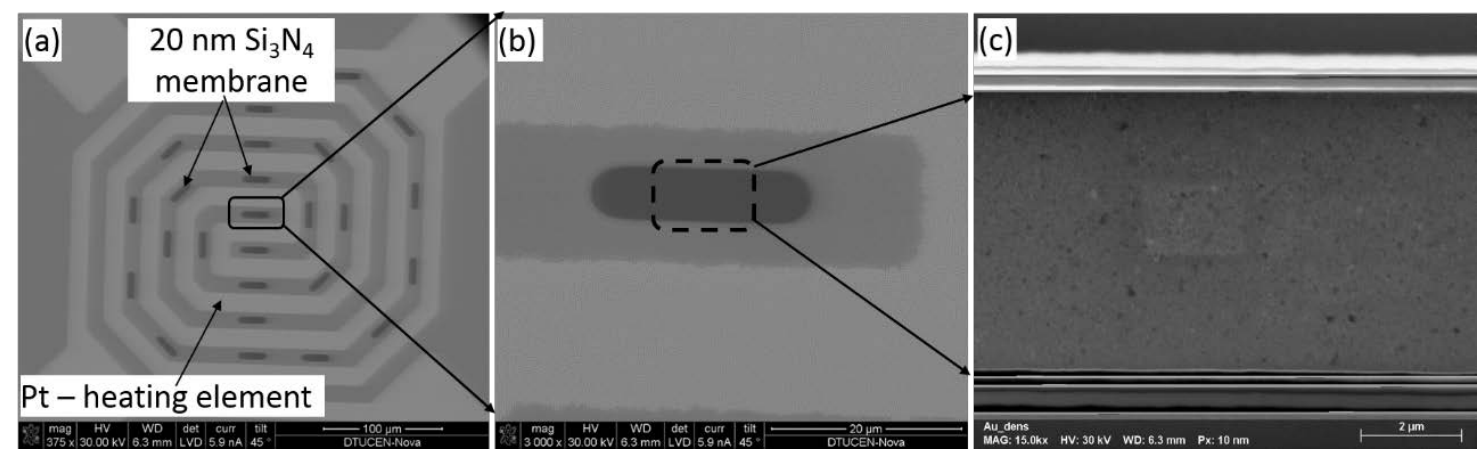
Figure 1: Microscope experimental set-up configuration for in-situ TKD heating in an SEM: (a) Secondary electron image of the MEMS heating chip with $15 \mathrm{~nm}$ Au film. (b) Zoom on the investigated window on the centre of the chip (c) STEM bright field image of the Au film on the centre window. (DOUBLE COLUMN)

The MEMS heating chips were mounted in an in house designed TKD holder. The temperature control of the MEMS chip was performed via the DENSsolution heating unit. The MEMS heating chips were mounted with the Au film facing the TKD camera (Au film positioned at the beam exit surface), since scattering events on the amorphous $\mathrm{Si}_{3} \mathrm{~N}_{4}$ membrane contribute to loss of the diffraction pattern as shown in [18]. Figure 2(a) shows the experimental set-up in the microscope chamber. The TKD experiment was performed in a FEI Nova Nanolab 600 SEM with a Bruker eFlash OPTIMUS ${ }^{T M}$ TKD detector, which allows on-axis TKD investigation of the sample. The chip was connected to the $45^{\circ}$ pre-tilted heating holder and the stage was tilted accordingly to allow the sample to be at $0^{\circ}$ tilt and give enough space for the OPTIMUS detector to be positioned underneath the sample. A low vacuum detector was connected to the microscope pole piece, and a water vapour pressure of $50 \mathrm{~Pa}$ was chosen for the experiments. The low vacuum mode was chosen to minimise drift and contamination of the sample, as demonstrated in $[13,47]$ drift minimization can be achieved by reduction of electron charging effect. The electrons leaving the sample surface collide with water vapour molecules ionizing them and balancing out the sample charge [47].The increase in chamber pressure however, can causes deterioration of the Kikuchi patterns. Utilizing a dedicated low vacuum detector that has a small beam gas path length, the adverse influence of chamber pressure on the Kikuchi pattern was minimized. Previous experiments on this sample have shown that the decrease in pattern quality is not significant at pressures below 60Pa.

Prior to the TKD investigation, the sample was plasma cleaned inside the microscope chamber using an Evactron decontaminator (XEI-Scientific, Redwood City, CA). The plasma cleaning was performed for 2 minutes at a pressure of 0.4 Torr and a Forward RF power of 12 Watts. The in-situ TKD experiment was performed at $30 \mathrm{kV}$ beam energy with a beam current of $4 \mathrm{nA}$, an aperture of $50 \mu \mathrm{m}$, a detector distance of $15 \mathrm{~mm}$ and a working distance of $5.7 \mathrm{~mm}$. An area of approximately $2.5 \times 2.5 \mu \mathrm{m}$ was investigated with a step size of $10 \mathrm{~nm}$ over a temperature range from $20^{\circ} \mathrm{C}$ to $500^{\circ} \mathrm{C}$ and with step size of $20 \mathrm{~nm}$ from $550^{\circ} \mathrm{C}$ to $1000^{\circ} \mathrm{C}$. A pattern resolution of $320 \times 240$ pixels was used, which resulted in an exposure time of $9 \mathrm{~ms}$ and a dynamical background correction was employed. In total, each mapped area was scanned for approximately $8 \mathrm{~min}$ (for the step size of 10 $\mathrm{nm}$ ) and $2 \mathrm{~min}$ (for the step size of $20 \mathrm{~nm}$ ). Furthermore, at some selected temperatures, the entire membrane was investigated (an area of $15 \mu \mathrm{m} \times 5 \mu \mathrm{m}$ ) with a step size of $50 \mathrm{~nm}$, to obtain an overview of the process over a larger area.

The sample was heated by an integrated heater coil (DENSsolution heating unit), allowing localised resistive heating directly on the sample support. The temperature readout was based on a resistivity measurement of the heater coil. Figure 2(b) shows the temperature versus time profile of the entire experiment. The temperature was increased between $50^{\circ} \mathrm{C}$ and $300^{\circ} \mathrm{C}$ by an increment of $10^{\circ} \mathrm{C}$ and after $300^{\circ} \mathrm{C}$ by an increment of $50^{\circ} \mathrm{C}$. The TKD measurements were always performed at the respective elevated temperatures with exception of $950^{\circ} \mathrm{C}$ and $1000^{\circ} \mathrm{C}$. During TKD measurements at $950^{\circ} \mathrm{C}$, it was observed that no Kikuchi patterns were obtained from the sample, therefore the sample was cooled down to $23^{\circ} \mathrm{C}$ and measured at this temperature. The same procedure was repeated for $1000^{\circ} \mathrm{C}$, at which temperature the sample was only kept for $1 \mathrm{~min}$, and measured at room temperature. All heating and cooling to the respective temperature was performed within milliseconds. 

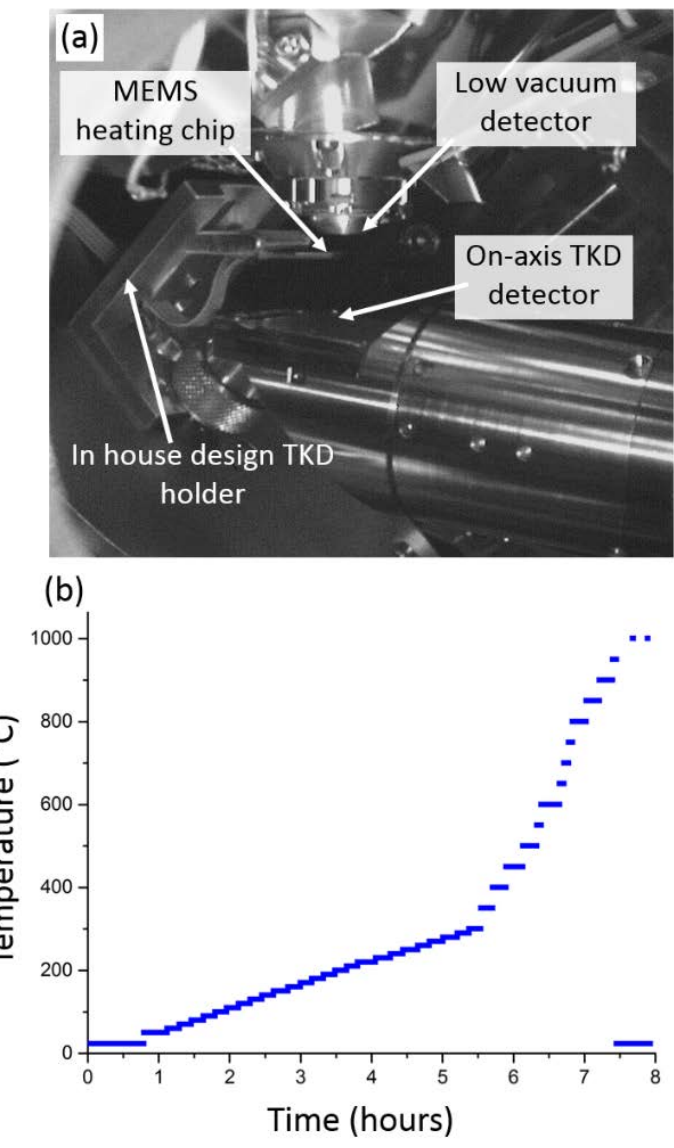

Figure 2: (a) Microscope chamber image at the experimental conditions (b) temperature versus time profile of the in-situ TKD experiment. (SINGLE COLUMN)

4 Data analysis was performed partly with ESPRIT (Bruker) and partly with OIM TSL (EDAX) software. 5 The ESPRIT was used for all pattern related data analysis, while OIM TSL was used for the analysis of the film microstructure. Prior to data analysis, the data was processed to define a grain and to eliminate dubiously indexed points. To this end, first a grain was defined as a region containing at least 3 data points with the same orientation and with a misorientation larger than $2^{\circ}$ to its neighbour. All data points that did not satisfy these criteria were removed from the datasets. Additionally zero solutions within a grain (points not touching a grain boundary) were cleaned (filled) to a maximum of 10 data points.

\section{Results}

As mentioned in the experimental details, the sample was plasma cleaned within the microscope chamber prior to the investigation. In Figure 3, an example of the advantages of conducting such cleaning is presented (sample: $20 \mathrm{~nm}$ of Au film deposited on a $20 \mathrm{~nm}$ Ti film). Figure 3(a) shows a measurement conducted prior and figure 3(b) after 2 minutes plasma cleaning. Both maps were measured with the same step size of $5 \mathrm{~nm}$ and the same pattern resolution, however the improvement in pattern intensity after plasma cleaning was so significant that the map in (b) was acquired more than 4 times faster than the map shown in (a), since the required exposure time could be reduced significantly. The improvement is also evident on the drift minimization (results from the 

in (b).
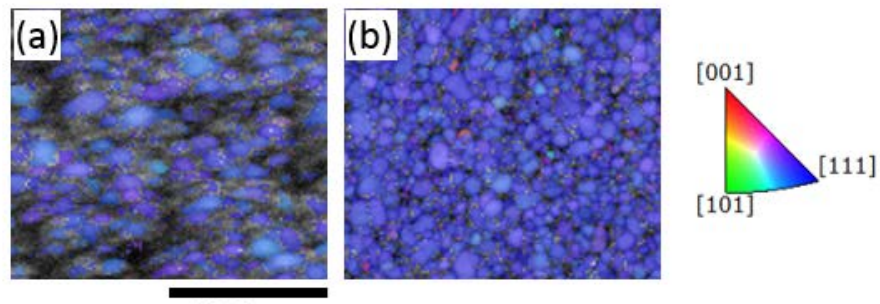

$300 \mathrm{~nm}$

Figure 3: Example of TKD data improvement as result of plasma cleaning for a $20 \mathrm{~nm}$ Au thin film deposited on a $20 \mathrm{~nm}$ Ti film. (a) Inverse pole figure map before and (b) after plasma cleaning of the sample inside the microscope chamber. (SINGLE COLUMN)

A preliminary investigation of the $15 \mathrm{~nm}$ Au film deposited by electron beam evaporation on $\mathrm{Si}_{3} \mathrm{~N}_{4}$ windows reveals that the microstructure of the film is bimodal, comprising of smaller grains with a diameter in the range of $30 \mathrm{~nm}$ and larger grains with a diameter in the $150 \mathrm{~nm}$ range and no evidence of film discontinuity could be observed. Due to the presence of finer grains, it is advantageous to perform measurements with a step size of 3 to $5 \mathrm{~nm}$, however such a small step size results in a relatively large measurement time (approximately 40 min to scan an area of $2 \times 2$ $\mu \mathrm{m})$. Considering that the current study dealt with the investigation of dynamic processes (grain growth and film dewetting) a compromise was found by investigating the studied area with a relatively large step size of $10 \mathrm{~nm}$, which allowed each map to be acquired in 8 minutes. Additionally, the size of the grains increased with the temperature and only in the lower temperature range, few grains were not indexed due to the chosen step size. Furthermore, at temperatures above $550^{\circ} \mathrm{C}$, the step size was further increased to $20 \mathrm{~nm}$, as the grains were considerably larger ( $d>100 \mathrm{~nm})$ and the dewetting process significantly faster. In this way, the area was scanned in only 2 min.

Due to this step size choice, it was difficult to evaluate the starting point of dewetting by means of observing the number of indexed points, as the number continues to increase, due to grain growth, even after dewetting has started. Therefore, it was necessary to evaluate the patterns on the nonindexed areas of the raw data set (this means every point in the map, independent of any data processing applied in the map) to have reliable evidence of the start of the dewetting process. Figure 4 shows two examples of a non-indexed pattern on the TKD map acquired at $210^{\circ} \mathrm{C}$ : Fig. 4 (b) on a dewetted area of the sample and Fig. 4(c) on an area with very fine grains (in the range of 10-20 $\mathrm{nm}$ ). The difference between the two patterns is evident. In Fig. 4(c) Kikuchi lines are clearly visible, but indexing is difficult due to the fact that the grain size is close to the physical resolution of the TKD technique, and due to the overlapping of the patterns at the grain boundaries. In Fig. 4(b) no pattern is observed, indicating lack of crystalline material, i.e. only the $\mathrm{Si}_{3} \mathrm{~N}_{4}$ substrate is present. 


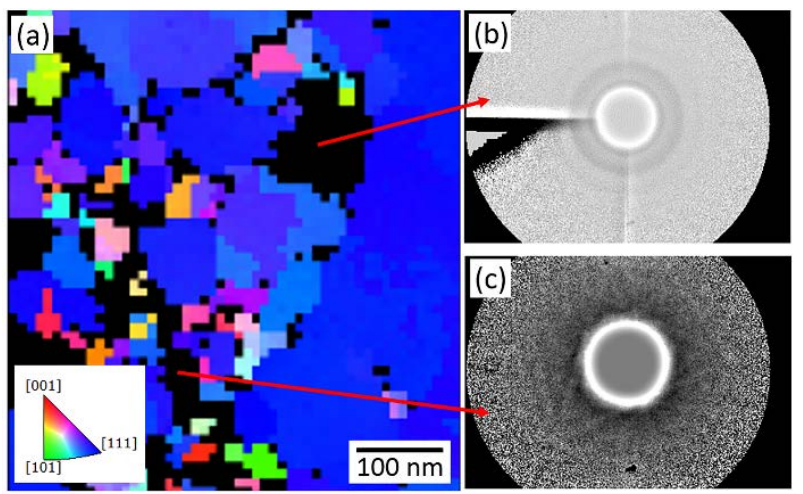

Figure 4: (a) IPF map of the growth direction of the $15 \mathrm{~nm}$ Au thin-film at $210^{\circ} \mathrm{C}$, showing in black the non-indexed areas consisting of dewetted regions and regions with very fine non-indexed grains. (b) Recorded camera signal from a dewetted area of the sample revealing no pattern and (c) nonindexed Kikuchi diffraction pattern from a fine grain region. (SINGLE COLUMN)

Figure 5 shows some of the inverse pole figure (IPF) maps of the film growth direction (out of plane) overlaid with pattern quality for temperatures varying from $20^{\circ} \mathrm{C}$ to $550^{\circ} \mathrm{C}$ (the full data with all temperature increments is shown in supplementary material). All TKD measurements presented in Figure 5 were performed at the respective temperatures and at the same window position. Sample drift can be observed when comparing the microstructure between maps (see supplementary material with all measurement increments) and it was more significant at lower temperatures (below $100^{\circ} \mathrm{C}$ ). The IPF maps reveal that the film has a strong [111] out-of-plane texture, and that grains with this preferential orientation tend to grow faster (abnormal grain growth), confirming results from previous studies $[34,35,48,49]$. Grains oriented along this preferential orientation are, from this point on, termed PO-grains and the ones deviating more than 15 degrees from it are termed nonpreferential oriented grains (non-PO). It is also observed that grain growth started at a temperature below $150^{\circ} \mathrm{C}$ while holes are clearly visible at $200^{\circ} \mathrm{C}$ (highlighted with a red circle). By investigating the patterns as described above (see Figure 4) at the position of the hole formed below $200^{\circ} \mathrm{C}$ (highlighted with red circle in Figure 5), it was possible to determine that the hole had already formed at $150^{\circ} \mathrm{C}$ (also highlighted with a red circle). Since saving all the pattern for all the maps requires extremely large space, Kikuchi patterns were only saved for selected map (i.e. selected temperatures), and it is therefore difficult to determine the exact temperature of formation of the first hole. Furthermore, all holes were formed in the vicinity of non-PO grains, which are also the sites that favour the growth of the holes. PO-grains, oriented along [111] can also delay hole growth, as it can be observed in the yellow rectangle area, where a hole is formed at $150^{\circ} \mathrm{C}$ and grows until it is completely surrounded by large PO-grains. The growth of this specific hole is then retarded until $500^{\circ} \mathrm{C}$, while other holes in the film continue to grow. 

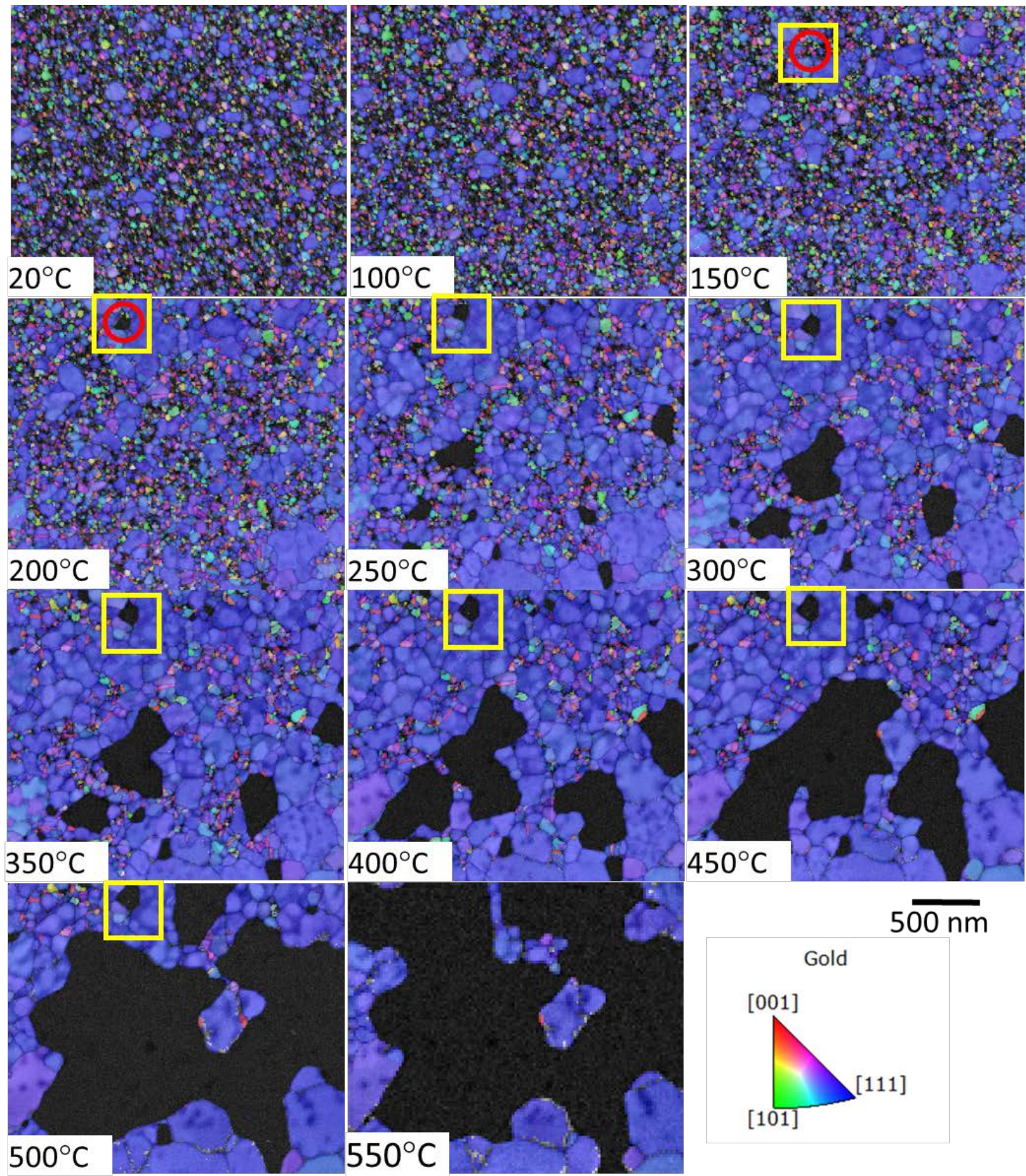

Figure 5: Out of plane IPF maps at selected temperatures overlaid with pattern quality map showing the grain growth, the formation of holes on non-PO grains and their subsequent growth. The red circle highlights one of the first formed holes, while the yellow rectangle illustrates the delayed hole growth of a hole surrounded by [111] PO oriented grains. (DOUBLE COLUMN)

Since TKD measurements provide a large amount of data for each scanned point in the map (54000 points at the step size of $10 \mathrm{~nm}$ ), quantitative data analyses can be obtained from this series of measurements. As mentioned before, and clearly observed in Figure 5, two classes of grains are distinct in the microstructure. Using this information, the orientation data was divided into two classes 
of grains: i) PO-grains defined as grains with [111]//growth direction (using tolerance angle of $15^{\circ}$ ) and ii) grains with other orientations (non-PO) and analysed separately. The average grain size diameter evolution is shown in Figure $6(\mathrm{a})$ for annealing temperatures up to $600^{\circ} \mathrm{C}$ for both grain classes separately. This graph confirms the images shown in Figure 5, revealing that grain growth is evident for $\mathrm{PO}$ grains after $120^{\circ} \mathrm{C}$. The $\mathrm{PO}$ grains are larger than non-PO ones from the starting microstructure and grow considerably faster. By a temperature of $220^{\circ} \mathrm{C}$, the $\mathrm{PO}$ average diameter increases three-fold, while non-PO grains maintain their average size of $33 \mathrm{~nm}$; up to $550^{\circ} \mathrm{C}$, practically only PO grains grow. Figure 6(b) shows the number of grains of each class during annealing, while Figure 6(c) shows the evolution of the fraction of indexed points for those two classes of grains and for the entire data set. These data confirm again the observation of the images in figure 5, showing that the fraction of indexed points and the number of non-PO grains start to decrease at an annealing temperature of $150^{\circ} \mathrm{C}$, which agrees with the starting point of hole formation (the dewetting process). On the other hand, the fraction of PO indexed points increases up to $350{ }^{\circ} \mathrm{C}$, while the number of $\mathrm{PO}$ grains starts to decrease already at $180^{\circ} \mathrm{C}$, indicating that these grains grow and coalesce before the dewetting of the film takes place.

(a)

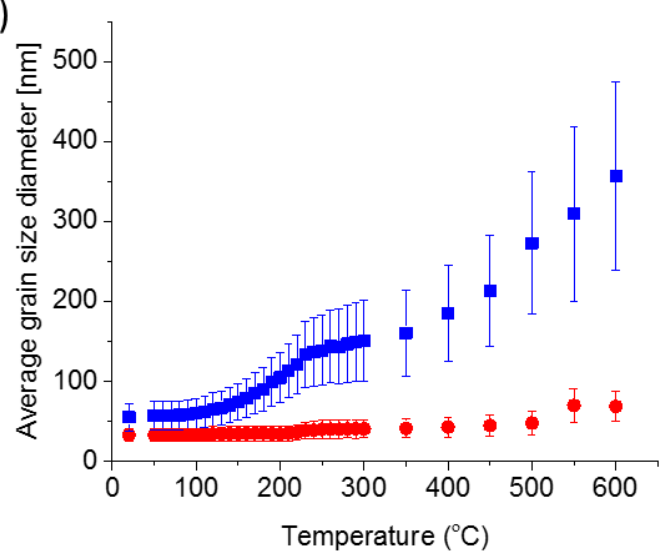

(c)

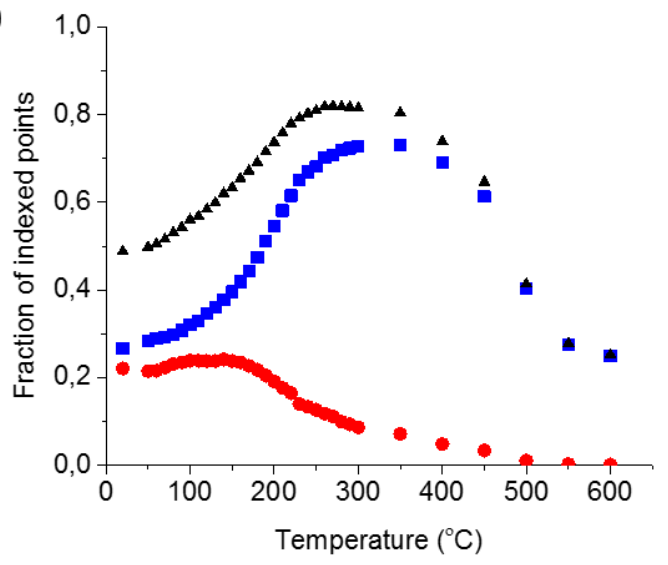

(b)

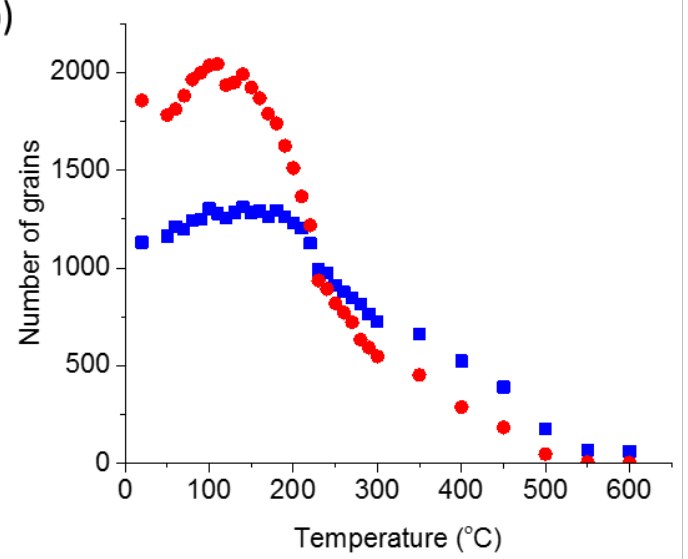

- PO grains

- non-PO grains

- all data

Figure 6: Microstructure evolution for the two classes of grains. Blue squares: Preferentially oriented grains (PO) are defined as grains with [111]//growth direction (using tolerance angle of 159 ); red circles: non- preferentially oriented grains (non-PO) defined as grains with other orientations. Black triangles: all data, both grain classes together. (a) Evolution of the average grain size diameter for the two classes of grains with temperature up to $600^{\circ} \mathrm{C}$, (b) evolution of the number of grains and (c) evolution of the fraction of indexed points with temperature. (DOUBLE COLUMN) 


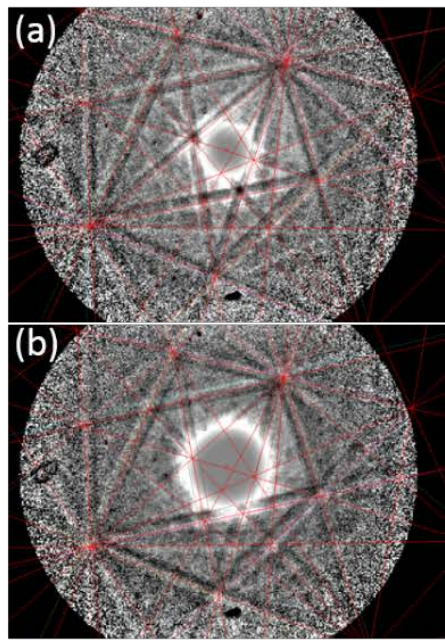
for the current investigation.
In solid state dewetting, once holes are formed they grow by edge retraction, resulting in mass accumulation and a local change in film thickness at the edge of the hole $[29,31,33]$. This local thickness variation can be clearly observed in the on-axis TKD patterns as the intensity of the transmitted primary beam is reduced with increasing thickness (Figure 7 a-e). The decreased intensity is observed as a decrease in the saturated area of the camera. Furthermore, the pattern contrast inverts when the film becomes significantly thicker (Figure $7 \mathrm{a}, \mathrm{b}$ and e) $[9,17,50]$. Both types of information can be qualitatively extracted from the TKD pattern and used to locate the areas where rim and fingers are formed $[29,31,33]$. Based on the intensity of the transmitted primary beam, it is easy to detect that the film is thinnest in the highlighted area $\mathbf{D}$ (finger) and thickest in $\mathbf{E}$ (rim). Indexing of patterns with inverted contrast is not optimal. Kikuchi lines are detected instead of bands, thus compromising the angular precision of the indexing routine. However, this error is not significant

Figure 7: TKD patterns at different locations of the sample, showing the thickness variation of the film during dewetting. C) IPF map overlaid with pattern quality map of the Au thin film at $600^{\circ} \mathrm{C}$, the letters in the map indicate the location of the TKD patterns shown in a), b), d) and e). (DOUBLE COLUMN)

Due to the very local heat achieved by MEMS-based heating devices, infrared radiation does not appear to significantly influence the CCD detector. Figure 8 shows on-axis TKD patterns obtained at different temperatures from approximately the same position. A clear signal to noise ratio reduction is observed with increasing temperature; however it is also noticeable that a reasonable pattern quality can be obtained even at high temperature and the indexing of these patterns posed no significant challenge for the software. 

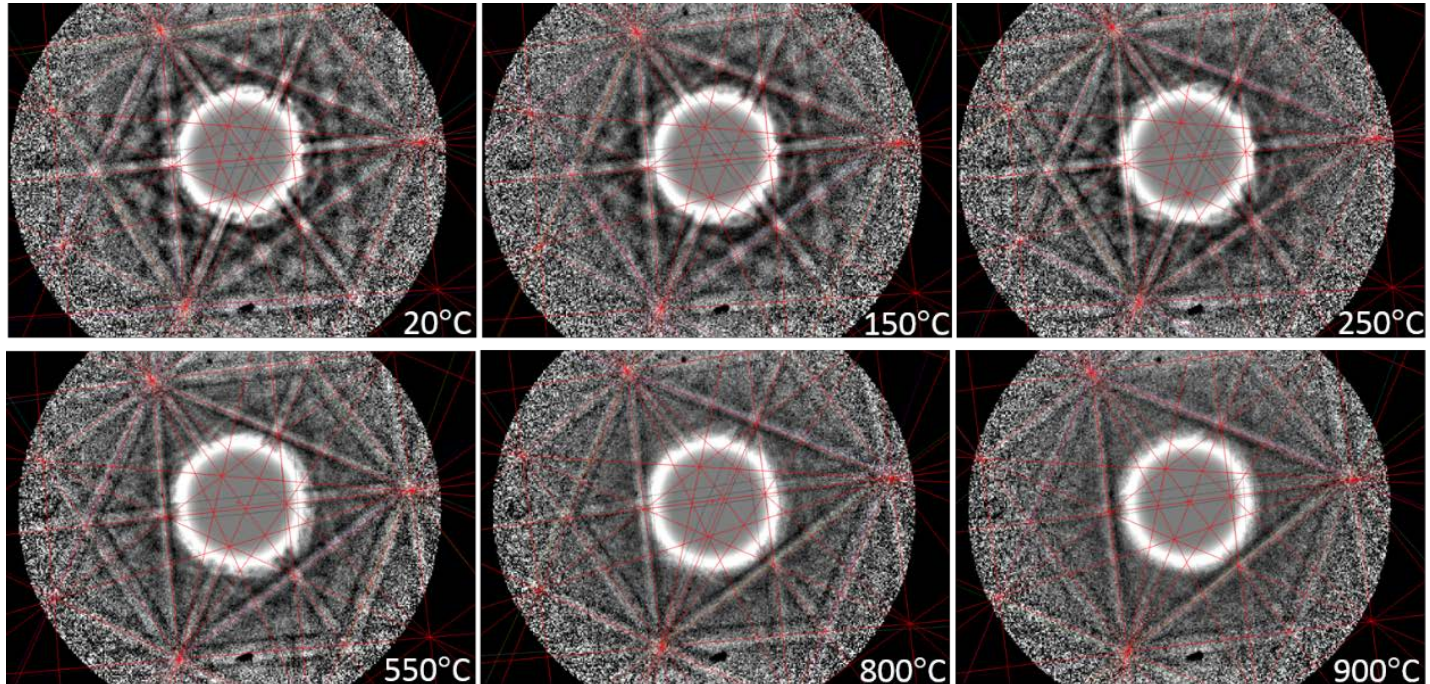

Figure 8: TKD patterns obtained from approximately the same position at different temperatures. (DOUBLE COLUMN)

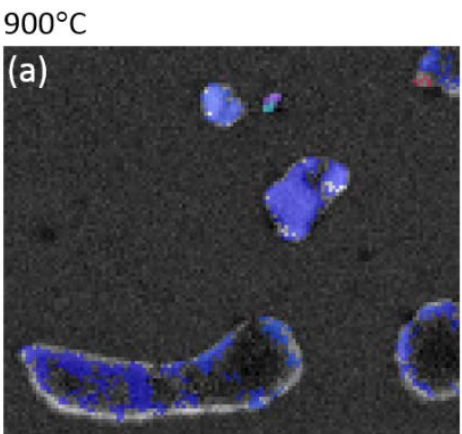

$950^{\circ} \mathrm{C}$
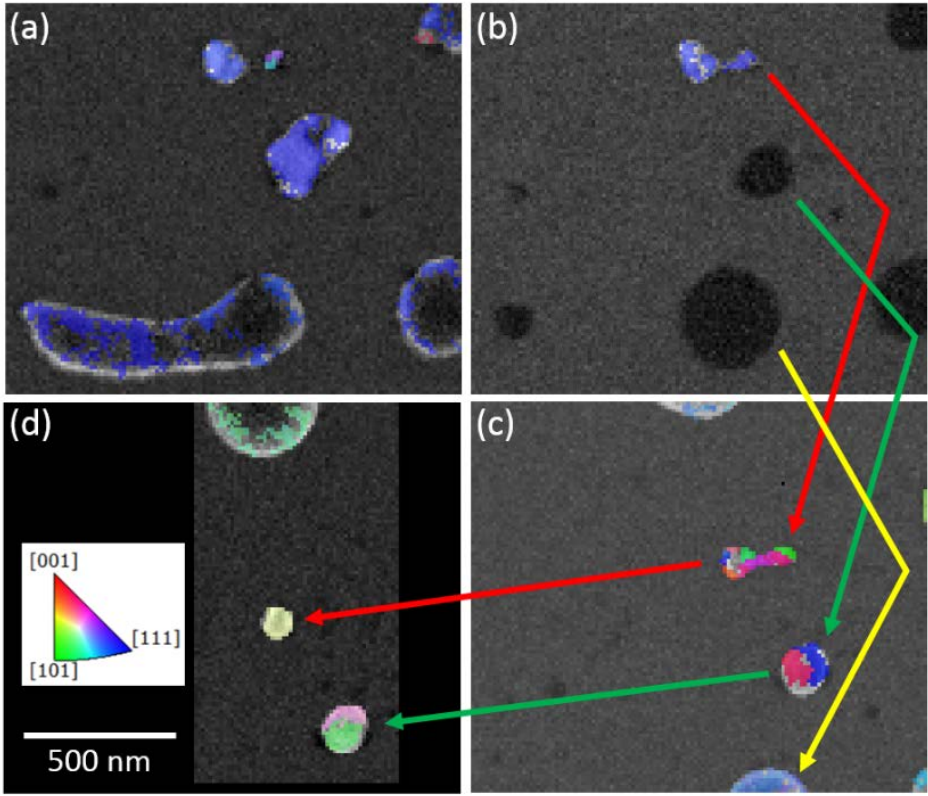

After $1000^{\circ} \mathrm{C}$ measured at $23^{\circ} \mathrm{C}$ After $950^{\circ} \mathrm{C}$ measured at $23^{\circ} \mathrm{C}$

Figure 9: IPF maps overlaid with pattern quality map of the film at high temperatures. a) Map performed at $900^{\circ} \mathrm{C}$, b) at $950^{\circ} \mathrm{C}$, c) after cooling from $950^{\circ} \mathrm{C}$ and measuring at room temperature, d) after cooling from $1000^{\circ} \mathrm{C}$ and measuring at room temperature. (DOUBLE COLUMN)

Obtaining TKD measurements at temperatures of $950^{\circ} \mathrm{C}$ and $1000^{\circ} \mathrm{C}$ was very challenging, because the longer the sample remained at these temperatures, less crystalline material there was available to measure, as the particles apparently started to melt. The sample was therefore kept at these temperatures for only 3 minutes $\left(950^{\circ} \mathrm{C}\right)$ (time to measure Figure $\left.9(\mathrm{~b})\right)$ and 1 min $\left(1000^{\circ} \mathrm{C}\right)$ and cooled down rapidly (in milliseconds) to room temperature $\left(23^{\circ} \mathrm{C}\right)$. The map acquired at $950^{\circ} \mathrm{C}$ (Figure 9(b)) shows clearly that most of the particles are not indexed at this temperature. Additionally, 
comparing the map acquired at $950^{\circ} \mathrm{C}$ (Fig. 9(b)) to the subsequent map acquired right after cooling down to $23^{\circ} \mathrm{C}$ (Figure 9(c)), it is evident that the particles have become crystalline again, however with a new orientation. The same behaviour was observed after cooling from $1000^{\circ} \mathrm{C}$ (Figure 9 (d)). Figure 10 shows the out-of-plane IPF maps of the entire membrane $(15 \times 5 \mu \mathrm{m})$ measured at (a) $850^{\circ} \mathrm{C}$, (b) $900^{\circ} \mathrm{C}$, (c) after cooling down from $950^{\circ} \mathrm{C}$ and (d) after cooling down from $1000^{\circ} \mathrm{C}$. The previous investigated area (shown in Figure 5, 9 and in the supplementary material) is highlighted with a green rectangle in the maps. Dewetting seems to be more advanced in the area where the investigation was conducted in comparison with the other areas of the membrane (the size of particles is significantly larger outside the green area, especially from $850^{\circ} \mathrm{C}$ to $950^{\circ} \mathrm{C}(\mathrm{a}-\mathrm{C})$ ). This beam influence, however does not appear to be very significant for the final size of the particles, as can be seen in the final result (Figure 10(d)). Related to this, it must also be pointed out that Au has a melting point at $1064^{\circ} \mathrm{C}$ : in this experiment, the particles are changing their orientation after cooling down from the high temperature treatment indicating that they might have melted. This lower melting point could be related to the beam influence but also to the low vacuum condition with a water pressure of $50 \mathrm{~Pa}$. Additionally, the [111] preferential orientation of the Au particles/film is completely lost after 1 minute at $1000^{\circ} \mathrm{C}$, and no preferential orientation is formed after cooling. The repeated heating to $1000^{\circ} \mathrm{C}$ and cooling of the sample leads to the reorientation of the Au particles each time (data not shown here).
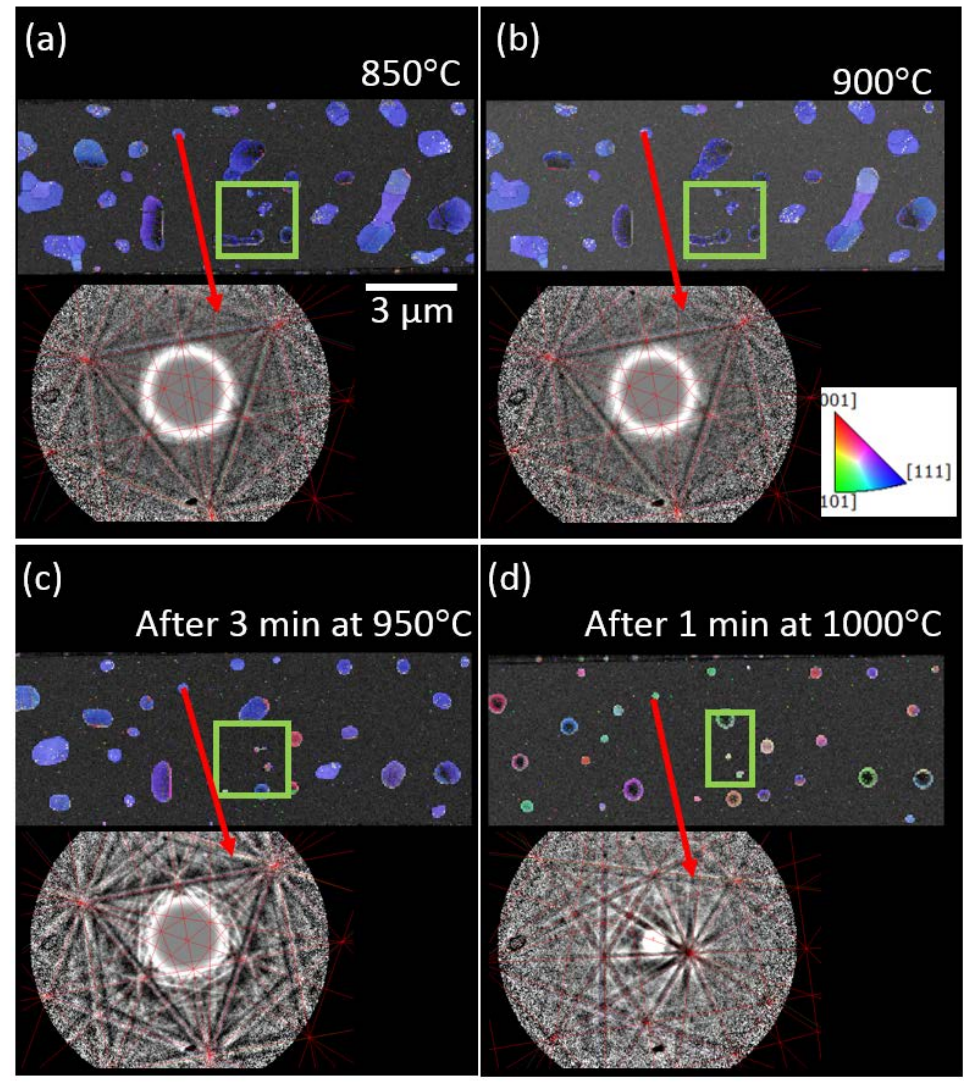

Figure 10: Overview IPF maps from the entire window at different temperatures and TKD patterns of the same particle obtained at the respective measurements a) at $\left.850^{\circ} \mathrm{C}, b\right) 900{ }^{\circ} \mathrm{C}, \mathrm{c}$ ) after annealing at $950^{\circ} \mathrm{C}$ for 3 minutes and measuring at room temperature and d) after annealing at $1000^{\circ} \mathrm{C}$ for 1 minute and measuring at room temperature. The green rectangle in all the maps highlights the area investigated in Figures 5, 9 and in the supplementary material. (DOUBLE COLUMN) 
As shown in Figure 9 and mentioned above, some particles annealed for 3 min at $950^{\circ} \mathrm{C}$ did not produce diffraction patterns at high temperature, and displayed new orientations after cooling, indicating that they had melted and crystallized. This information raises a question about the lower pattern quality observed at high temperature. Is the decrease in pattern quality related to infrared radiation, or is the crystal disorder caused by the proximity of the melting point playing a role here as well? To answer this question, a comparison was made between the pattern at high temperature on the central window and on a window far away from the centre of the MEMS heating holder. It is well known that there is a temperature gradient from the centre membrane to the outer membrane; this gradient was shown by Niekiel et al. [51] to be in the order of $150^{\circ} \mathrm{C}$. Considering this temperature gradient, when the holder is set to $900^{\circ} \mathrm{C}$ at the central window, a window at the edge should be at approximately $750^{\circ} \mathrm{C}$ : the infrared radiation is independent of which window the measurement is performed on. However, dewetting at the outer window is not so advanced due to the lower temperature and the melting of the Au has not yet close. Figure 11(a) shows an IPF map and a pattern obtained from the central membrane at $900^{\circ} \mathrm{C}$ and Fig. 11 (b) shows the map and the pattern obtained from the outer membrane with the heating set to the nominal value of $900^{\circ} \mathrm{C}$ (but with the film at the estimated value of $750^{\circ} \mathrm{C}$ ). This result suggests i) that infrared radiation is not drastically influencing the camera, as the patterns are sharp and with a high signal to noise ratio on the outer membrane, but are not on the central membrane and ii) that the loss of sample crystallinity is the main factor causing the degradation of the pattern quality at such high temperatures.
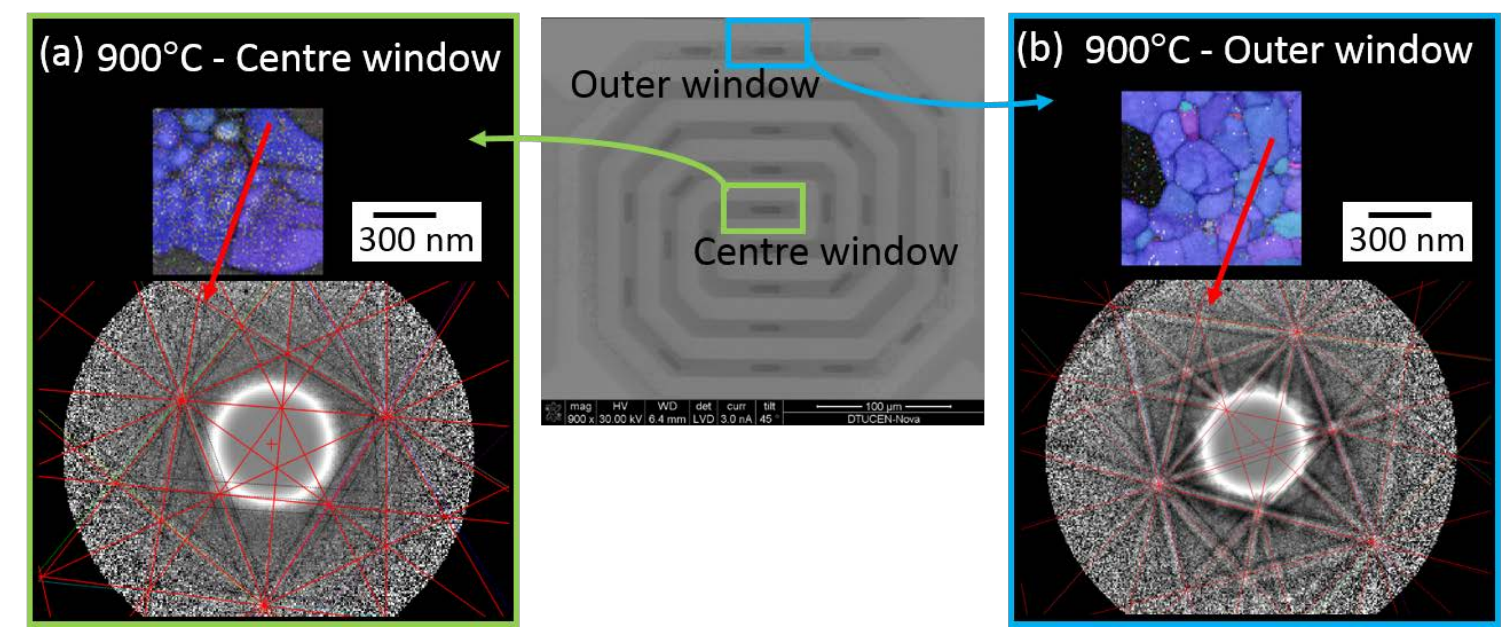

Figure 11: TKD map and Kikuchi pattern at $900^{\circ} \mathrm{C}$ in two locations of the MEMS heating holder: (a) on the central window and (b) on the outer window. The temperature gradient between the windows was estimated to be in the order of $150^{\circ} \mathrm{C}$ [51]. (DOUBLE COLUMN)

After the experiment was finished, the sample was placed upside down for SEM imaging (with the Au particles facing the beam entrance surface). Figure 12(a) shows a secondary electron image obtained with the through lens detector of the particles at the investigated area with an estimated size of the particles highlighted in the image; Fig. 12(b) shows a TKD measurement of the same particles, revealing how TKD orientation maps can be obtained from Au particles of almost $500 \mathrm{~nm}$ in thickness. 


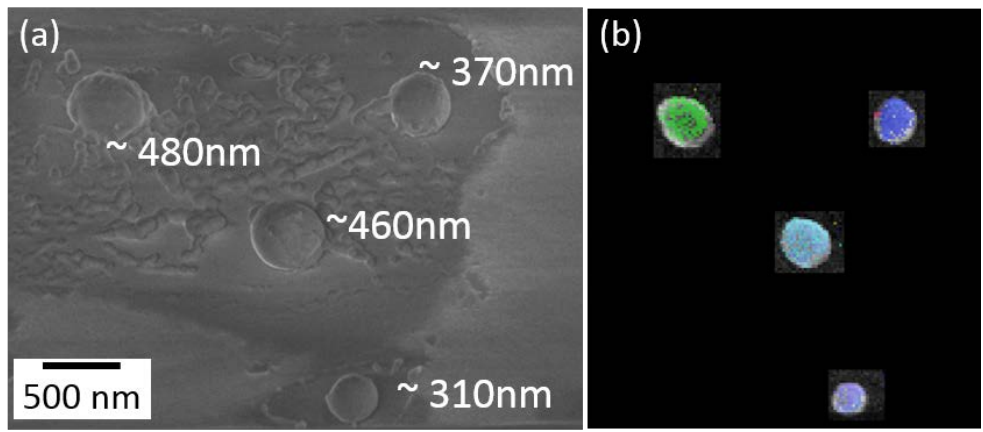

Figure 12: (a) Secondary electron image of the Au nanoparticles after the experiment with highlighted estimation of the particles size. (b) TKD orientation map of the same nanoparticles in (a). (SINGLE COLUMN)

\section{Discussion}

It is important to point out that, although knowledge about thin-film Au dewetting was obtained in this work, this study primarily used Au dewetting as an example for investigating the possibilities of insitu TKD. Therefore, although some microstructure characteristics associated with the dewetting of Au have been presented and briefly discussed in this paper, a detailed investigation of the process is beyond the scope of this work and will be discussed in future reports. In this section, the in-situ TKD results will be discussed, areas of potential improvement will be addressed and the prospects of the technique will be outlined.

Measurement speed is an extremely important parameter for investigating dynamic events. Often the increase of the measurement speed is associated with compromises. In this work, a compromise was made in terms of spatial resolution (using a step size of $10 \mathrm{~nm}$ instead of more appropriate 3 $\mathrm{nm}$ ) to maintain reasonable measurement area and time. The measurement time of 8 minutes was acceptable at the lower temperature range, but not necessary at higher temperatures (above $500^{\circ} \mathrm{C}$ ), where the process was faster. Conversely, since both dewetting and grain growth commenced before this temperature of $500{ }^{\circ} \mathrm{C}$ was reached, and all microstructural features became larger than the starting microstructure, it was possible to increase the measurement speed by further increasing the step size at high temperatures.

Further improvements in the measurement speed can be achieved by increasing beam current, by decreasing pattern resolution, or conducting the experiments in high vacuum. Increasing beam current is associated with a decrease in spatial resolution and an increase in sample contamination. Decreasing pattern resolution can be a good solution, especially when the patterns are of very good quality, as it has been shown in this example. However, indexing can be compromised on areas with low pattern quality, particularly at high temperature and on thicker samples, where contrast inversion of the patterns is observed. The vacuum condition is also related to pattern quality, since the water vapour of the low vacuum mode can degrade the diffraction pattern quality [47].

Prior to any in-situ experiments, all these parameters must be investigated for every individual sample within the objectives of the work, so that the optimized conditions can be found. In this study, a further increase in beam current $(I>4 \mathrm{nA})$ had the same effect as increasing the step size, however with the disadvantage of increased contamination. Since an increase of the step size was more significant in the initial steps of the experiment, while increased contamination would compromise the pattern quality at higher temperatures, the increase in step size was chosen as the best compromise. Decreasing the pattern resolution was also not favourable for the high temperature 
patterns, particularly due to the local thickness variation of the film at high temperature and the further degradation of the pattern associated with that. The low vacuum condition chosen in this experiment, originates from experience with other samples deposited on silicon nitride membranes and measured with TKD. It was observed that both drift and charging were minimised in low vacuum conditions with minimal pattern degradation. Additionally, a low vacuum condition contributes to reduced sample contamination, due to reaction of water molecules with the carbon hydroxide forming on the sample surface. Further investigation and experience of high temperature measurements are required to properly evaluate the best vacuum for optimized pattern acquisition conditions.

Plasma cleaning of the sample prior to TKD experiments, on the other hand, revealed only advantages, as shown in the maps of Figure 3 . The improvement in pattern quality and the consequently enhanced measurement efficiency is crucial for dynamic experiments, which require fast and multiple scans in the same position. The advantage of plasma cleaning is however not restricted to dynamic investigations and is recommended for all high resolution TKD experiments. Plasma cleaning the sample inside the microscope chamber is advantageous, as the chamber and the holder are cleaned simultaneously.

Although solid state dewetting is a well-studied process, there are still areas to be explored, as for example the starting point of hole formation. The observations shown in Figure 4 indicate that TKD has the potential to provide answer to that question, as there is a clear distinction between the detector signal obtained from very fine grains (here not always indexed by the software) and holes. Using this distinction in an automated way may allow one to track the exact position of hole formation, and fully characterize the microstructure at this location. However, in this study only a manual investigation was performed due to software restrictions. It is important to point out that the minimum size of a hole that can be detected by this methodology is limited by the physical spatial resolution of TKD in on-axis configuration, which has been shown in [52] to be in the order of $12 \mathrm{~nm}$.

The detailed investigation of hole formation will be subject of another study, since for such a detailed investigation a finer map step size would be required, so that all the possible sites for hole formation, like grain boundaries and triple junctions, are well characterized from the initial microstructure. Furthermore, this method requires the Kikuchi patterns to be saved for every map at all temperature increments, which was not the case for this investigation. Such a study would also benefit from the combination of high resolution STEM images and TKD orientation maps for a more comprehensive characterization of the hole's nucleation sites. This combination was not applied in the current study, because each image technique requires a different detector insertion length, and consequently is combined with increased experimental time and drift. Such a combination is however possible, particularly when pseudo-in-situ experiments (heating and cooling within the microscope, but measuring always at room temperature) are conducted and when using the STEM and TKD combination as presented by Brodusch and co-workers $[11,15]$ in the off-axis TKD configuration.

Figures 5 and 6 illustrate some of the information that can be obtained by in-situ dewetting of an Au film in combination with TKD. Evolution of grain size, texture, grain boundaries, and holes, can be tracked throughout the process with high resolution, accuracy and statistical significance. These figures, in combination with the full data presented in the supplementary materials, clearly reveal that grain growth occurs predominantly on grains with [111] out of plane orientations, and that it starts at relatively low temperatures $\left(T<150^{\circ} \mathrm{C}\right)$. This abnormal grain growth of preferential oriented grains is well known and has been proposed to be a surface-energy-driven secondary grain growth mechanism $[34,35,48,49]$. Furthermore, the first observed hole was also formed below $150^{\circ} \mathrm{C}$. However, to the authors knowledge, most of the published microscopy studies on dewetting concentrate on high temperature investigations $\left(T>400^{\circ} \mathrm{C}\right)$. Taking the current results in 
consideration it might be important to set the focus on understanding in more detail the microstructure modification occurring in thin films at the lower temperature range, particularly with respect to the fabrication and performance of nanodevices.

The in-situ experiments presented in this work have shown that TKD measurements on Au thin-films can be performed at temperatures varying from $20^{\circ} \mathrm{C}$ to $900^{\circ} \mathrm{C}$ without considerable problems (see Figure 8 and supplementary material), but measurements at $950^{\circ} \mathrm{C}$ and $1000^{\circ} \mathrm{C}$ were impossible (see Figure 9). The temperature limit in the current study was however imposed by the material and its proximity to the melting temperature (as demonstrated in Figure 11) and not by the TKD camera or the heating holder. Due to the very local heating of such MEMS heating holders, infrared radiation is apparently minimised. The comparison of patterns obtained in the inner and outer membranes, while heating the sample to $900^{\circ} \mathrm{C}$ (Figure 11), has given a clear indication that the detector is not significantly influenced by infrared radiation. The decrease in signal to noise ratio, observed at high temperatures (Fig. 8 and 9) is most probably a result of crystal disorder, being a consequence of the proximity of the melting point of the sample. Repeating the same experiment with a high melting point material $\left(\mathrm{T}_{\mathrm{m}}>1300^{\circ} \mathrm{C}\right.$, which is the holder limiting temperature) provides a better indication of the real limit of TKD at high temperature.

The lower melting point of the Au particles observed in this work can be related to the interaction of the electron beam with the sample, but also to lattice vibrations increasing locally the temperature and to the vacuum conditions. In figure 10c for example, it can be observed that after exposing the sample for 3 minutes at $950^{\circ} \mathrm{C}$, only the area, which has been previously investigated (highlighted in green) shows particles with different crystal orientation, indicating that only this area could have already reached the melting point and crystallized again after cooling. This suggests that beam interaction plays a role in the process. On the other hand after heating up the sample to $1000^{\circ} \mathrm{C}$ and cooling down again all particles changed their orientation. Since the melting point of Au particles with diameter above $100 \mathrm{~nm}$ should be equal to the bulk material [53], this deviation of approximately $60^{\circ} \mathrm{C}$ suggests that other factors play a role. Furthermore, throughout the experiment the temperature measured at the heating coil is assumed to be the same as the one in the sample, based on the results presented in [51], where very little deviation between the sample temperature, and the read-out temperature was observed. Further experiments to better understand this effect would be of great interest, but are beyond the scope of this work.

It has being widely discussed in TKD studies that the technique is significantly influenced by sample thickness $[1,12,17,18,24,54]$. In particular, on-axis TKD patterns reveal different features depending on the thickness of the sample [17]. In on-axis TKD the thickness variation can be identified by the intensity of the directly transmitted primary beam signal at the detector positioned below the sample. The thicker the sample, the less saturated the camera is and thereby a smaller area of the camera appears overexposed. In this work, this thickness dependence is very useful, as it gives an indication about the local thickness variation caused by the mass accumulation of the Au during dewetting (see Figure 7). Currently this additional information can only be treated qualitatively, as there may be other parameters influencing this intensity, as for example crystal orientation. Kikuchi pattern contrast inversion with increasing film thickness poses a significant challenge to the automated indexing routine of the TKD software, and deteriorates the angular precision of indexing. Improvements to the indexing routine to take this effect into account are of high importance. As long as such improvements are not established, evaluating local orientation changes during the dewetting process should be carried out with caution, as when rims are formed and the thickness increases, contrast inversion can indicate a false local orientation change (grain rotation). 
Although the TKD patterns are significantly influenced by sample thickness, it is possible to obtain indexable patterns from Au films with a thickness from $15 \mathrm{~nm}$ to Au particles of almost $500 \mathrm{~nm}$, as shown in Figure 12. However, from Figure $10(\mathrm{~d})$ it is clear that there is a maximum thickness limit, as particles with a diameter larger than $500 \mathrm{~nm}$ could not be fully indexed. Especially at the centre of those particles, where the thickness is approximately equal to the particle diameter, no Kikuchi patterns were observed. This thickness range is material dependent and has already been demonstrated for some materials $[12,17,18,24]$. It is important to point out, that both spatial resolution and angular precision are considerably reduced on large sample thicknesses, due to beam broadening and dynamical diffraction effects causing contrast reversal, complicating the indexing of the patterns. The determination of the precise thickness range, over which high resolution orientation maps of $\mathrm{Au}$ can be obtained, requires a systematic pattern contrast investigation on a known thickness. This is not the case of this experiment, as the thickness is varying during the experiment, and although indication of this variation is present on the pattern, no absolute value can be extracted from it. Therefore, the results provided here indicate only the thickness range in which indexable patterns can be obtained, but not the range in which high resolution TKD orientation data can be acquired.

MEMS-based heating holders are widely used in TEM heating experiments due to low drift, low mass and fast response. These advantages are very useful for in-situ TKD. The results presented in this work also reveal that infrared radiation is minimised and TKD investigations can be performed at very high temperatures. In the literature it has been described how the chip membrane tends to bulge at high temperature [51]. Niekiel et al. reported bulging of up to $11 \mu \mathrm{m}$ at $800^{\circ} \mathrm{C}$ [51]. Such bulging of the membrane would result in a change of detector geometry (working distance, detector distance, and consequently pattern centre calibration), which is directly related to the indexing routine of the system. However, as those geometrical parameters are defined in the millimeter range, a membrane bulging of approximately $11 \mu \mathrm{m}$ should have a negligible influence on pattern calibration. Furthermore, since the capture angle of the TKD patterns is large enough to allow indexing of several bands and multiple zone axis, this slight geometrical misalignment is presumably not critical for a total orientation determination. No clear indication of film bulging could be observed during the experiments. However, $11 \mu \mathrm{m}$ of membrane bulging would contribute to an orientation change of the grains causing errors in the indexing. Since bulging of the membrane is expected at relatively high temperatures, where the particles thickness also contributes to the decrease in orientation precision, further experiments would be required to confirm if bulging of the membrane is influencing the TKD orientation precision or not.

Beam induced thermal drift, on the other hand, was noticeable between maps and substantially stronger at temperatures below $200^{\circ} \mathrm{C}$, in the order of 200-300 nm. Map distortion was also observed, and again more significant at lower temperature, therefore most probably associated with beam induced effect. Due to the lower energy of the electrons in the SEM, the beam interaction with the sample is significantly larger than in the TEM and consequently the beam induced thermal effect is more significant. Thermal drift is quite significant in TKD, and has been reported by various authors $[6,21,24,55]$. The significant decrease of sample drift after a couple of hours during the experiment indicates that the sample stabilizes under the beam and drift is minimised with time. The thermal effect of the beam could also be influencing the dewetting process, as it was observed in Figure 10(a-c), where dewetting is more advanced in the investigated areas (highlighted in green) compared to other areas of the membrane. Furthermore it could be that the enhanced conductivity at higher temperatures is also playing a role in reducing drift effects. The detailed investigation of these effects is, however, beyond the scope of this publication. 
Although this study was only performed with the on-axis TKD configuration, it is not restricted to this configuration. Measurement speed, however, could be a significant challenge for the off-axis configuration, as it has been reported that on-axis TKD can be up to 20 times faster than off-axis TKD [55]. Conducting a pseudo-in-situ experiment should not be a problem for any configuration. One advantage of off-axis TKD configuration, would be the possibility of obtaining dark field images of the sample simultaneously with the orientation map, without camera movements or the combination with a STEM detector located below the sample as proposed in $[11,15]$.

It is also important to mention that the oversaturated area in the centre of the screen does not noticeably compromise the indexing of the pattern, as also shown in [52], as bands are detected even though they are partially oversaturated. The band contrast map on the other hand, is disturbed by the acquisition of the transmitted beam intensity, leading to conditions where it is impossible to distinguish between the dewetted area and the non-indexed finer grains by means of the pattern quality. Software improvements in this regard would be very advantageous.

MEMS heating holders are certainly ideal for investigation of nanoparticles, nanowires and thin films, however they are not limited to those samples. FIB lift out lamellas can also be positioned on the membranes as demonstrated in [56].

\section{Conclusions}

The combination of very local heating and TKD is well suited for studying thin-film dewetting processes and has a large prospective in materials research. The small volume and very local heating minimises infrared radiation, which does not significantly compromise TKD patterns at high temperature. Drift is only significant at the beginning of the experiments, and could be minimised by allowing the sample to stabilise under the beam before starting the experiments. Plasma cleaning the sample prior to the experiments is an effective way to increase measurement speed and improve pattern quality. TKD patterns can be obtained from Au in a thickness range between 15 and $500 \mathrm{~nm}$, although contrast inversion compromises the precision of orientation determination on thick samples. Therefore, software improvements for dealing with the effect of thickness variation on the patterns are very much required. This work nicely demonstrates the capability of high temperature TKD characterization of nanocrystalline thin films. The combination of high resolution imaging and orientation mapping under the influence of temperature in an SEM opens opportunities for scientific studies that were not accessible previously. Further development of even more stable MEMS heaters and software will pave the way for making in-situ TKD of low-dimensional materials routinely accessible as a complementary characterization technique within materials science.

\section{Acknowledgments}

Adam Fuller, DTU Center for Electron Nanoscopy (Cen), is acknowledged for his support for making the in-situ experiments possible. Bruker Nano $\mathrm{GmbH}$ (BNA) is gratefully acknowledged for the loan of the OPTIMUSTM TKD detector head.

\section{Data availability}

The raw/processed data required to reproduce these findings cannot be shared at this time due to technical or time limitations.

\section{References}

[1] R.R. Keller, R.H. Geiss, Transmission EBSD from $10 \mathrm{~nm}$ domains in a scanning electron 
microscope, J. Microsc. 245 (2012) 245-251. doi:10.1111/j.1365-2818.2011.03566.x.

[2] R.H. Geiss, R.R. Keller, D.T. Read, Transmission electron diffraction from nanoparticles , nanowires and thin films in an SEM with conventional EBSD equipment *, 16 (2010) 5-6. doi:10.1017/S14319276100.

[3] M.J. Burch, D.T. Harris, C.M. Fancher, J.-P. Maria, E.C. Dickey, Domain Structure of Bulk and Thin-Film Ferroelectrics By Transmission Kikuchi Diffraction, Microsc. Microanal. 21 (2015) 777-778. doi:10.1017/S1431927615004687.

[4] B. Wickman, A. Bastos Fanta, A. Burrows, A. Hellman, J.B. Wagner, B. Iandolo, Iron Oxide Films Prepared by Rapid Thermal Processing for Solar Energy Conversion., Sci. Rep. 7 (2017) 40500. doi:10.1038/srep40500.

[5] S. Alekseeva, A.B. da S. Fanta, B. Iandolo, T.J. Antosiewicz, F.A.A. Nugroho, J.B. Wagner, A. Burrows, V.P. Zhdanov, C. Langhammer, Grain boundary mediated hydriding phase transformations in individual polycrystalline metal nanoparticles, Nat. Commun. 8 (2017) 1084. doi:10.1038/s41467-017-00879-9.

[6] P.W. Trimby, Y. Cao, Z. Chen, S. Han, K.J. Hemker, J. Lian, X. Liao, P. Rottmann, S. Samudrala, J. Sun, J.T. Wang, J. Wheeler, J.M. Cairney, Characterizing deformed ultrafinegrained and nanocrystalline materials using transmission Kikuchi diffraction in a scanning electron microscope, Acta Mater. 62 (2014) 69-80. doi:10.1016/j.actamat.2013.09.026.

[7] D.A.M. de Winter, R.J. Mesman, M.F. Hayles, C.T.W.M. Schneijdenberg, C. Mathisen, J.A. Post, In-situ integrity control of frozen-hydrated, vitreous lamellas prepared by the cryofocused ion beam-scanning electron microscope, J. Struct. Biol. 183 (2013) 11-18. doi:10.1016/j.jsb.2013.05.016.

[8] D.C.K. Wong, W.K. Yeoh, P.W. Trimby, K.S.B. De Silva, P. Bao, W.X. Li, X. Xu, S.X. Dou, S.P. Ringer, R.K. Zheng, Characterisation of nano-grains in MgB2 superconductors by transmission Kikuchi diffraction, Scr. Mater. 101 (2015) 36-39. doi:10.1016/j.scriptamat.2015.01.012.

[9] S. Suzuki, Features of Transmission EBSD and its Application, Jom. 65 (2013) 1254-1263. doi:10.1007/s11837-013-0700-6.

[10] S.Y. Zhang, Y.J. Zhang, W.M. Kwek, L.S. Goi, A.D. Trigg, L.J. Tang, Application of transmission EBSD on high topography surface Aluminum thin film, in: 2014 IEEE 16th Electron. Packag. Technol. Conf., IEEE, 2014: pp. 828-832. doi:10.1109/EPTC.2014.7028394.

[11] N. Brodusch, H. Demers, R. Gauvin, Nanometres-resolution Kikuchi patterns from materials science specimens with transmission electron forward scatter diffraction in the scanning electron microscope, J. Microsc. 250 (2013) 1-14. doi:10.1111/jmi.12007.

[12] P.W. Trimby, Orientation mapping of nanostructured materials using transmission Kikuchi diffraction in the scanning electron microscope, Ultramicroscopy. 120 (2012) 16-24. doi:10.1016/j.ultramic.2012.06.004.

[13] K. Kunze, Crystal orientation measurements using SEM-EBSD under unconventional conditions, Powder Diffr. 30 (2015) 104-108. doi:10.1017/S0885715615000263.

[14] K.P. Rice, Y. Chen, T.J. Prosa, D.J. Larson, Implementing Transmission Electron Backscatter Diffraction for Atom Probe Tomography, Microsc. Microanal. 22 (2016) 583588. doi:10.1017/S1431927616011296.

[15] N. Brodusch, H. Demers, M. Trudeau, R. Gauvin, Acquisition parameters optimization of a 
transmission electron forward scatter diffraction system in a cold-field emission scanning electron microscope for nanomaterials characterization, Scanning. 35 (2013) 375-386. doi:10.1002/sca.21078.

[16] R.H. Geiss, K.P. Rice, R.R. Keller, Transmission EBSD in the Scanning Electron Microscope, Micros. Today. 21 (2013) 16-20. doi:10.1017/S1551929513000503.

[17] E. Brodu, E. Bouzy, J.-J. Fundenberger, Diffraction contrast dependence on sample thickness and incident energy in on-axis Transmission Kikuchi Diffraction in SEM, Ultramicroscopy. 181 (2017) 123-133. doi:10.1016/j.ultramic.2017.04.017.

[18] K.P. Rice, R.R. Keller, M.P. Stoykovich, Specimen-thickness effects on transmission Kikuchi patterns in the scanning electron microscope., J. Microsc. 254 (2014) 129-36. doi:10.1111/jmi.12124.

[19] R. van Bremen, D. Ribas Gomes, L.T.H. de Jeer, V. Ocelík, J.T.M. De Hosson, On the optimum resolution of transmission-electron backscattered diffraction (t-EBSD), Ultramicroscopy. 160 (2015) 256-264. doi:10.1016/j.ultramic.2015.10.025.

[20] K.P. Rice, Y. Chen, R.R. Keller, M.P. Stoykovich, Beam broadening in transmission and conventional EBSD, Micron. 95 (2017) 42-50. doi:10.1016/j.micron.2016.12.007.

[21] J.J. Fundenberger, E. Bouzy, D. Goran, J. Guyon, H. Yuan, A. Morawiec, Orientation mapping by transmission-SEM with an on-axis detector., Ultramicroscopy. 161 (2016) 1722. doi:10.1016/j.ultramic.2015.11.002.

[22] B.T. Jacobson, D. Gavryushkin, M. Harrison, K. Woods, Angularly sensitive detector for transmission Kikuchi diffraction in a scanning electron microscope, Proc. SPIE SPIE. 9376 (2015) 93760K. doi:10.1117/12.2083520.

[23] S. Vespucci, A. Winkelmann, K. Mingard, D. Maneuski, V. O'Shea, C. Trager-Cowan, Exploring transmission Kikuchi diffraction using a Timepix detector, J. Instrum. 12 (2017) C02075-C02075. doi:10.1088/1748-0221/12/02/C02075.

[24] G.C. Sneddon, P.W. Trimby, J.M. Cairney, Transmission Kikuchi diffraction in a scanning electron microscope: A review, Mater. Sci. Eng. R Reports. 110 (2016) 1-12. doi:10.1016/j.mser.2016.10.001.

[25] M. Abbasi, D.-I. Kim, H.-U. Guim, M. Hosseini, H. Danesh-Manesh, M. Abbasi, Application of Transmitted Kikuchi Diffraction in Studying Nano-oxide and Ultrafine Metallic Grains., ACS Nano. 9 (2015) 10991-1002. doi:10.1021/acsnano.5b04296.

[26] G. Proust, P. Trimby, S. Piazolo, D. Retraint, Characterization of Ultra-fine Grained and Nanocrystalline Materials Using Transmission Kikuchi Diffraction, J. Vis. Exp. (2017) e55506-e55506. doi:10.3791/55506.

[27] A. Garner, A. Gholinia, P. Frankel, M. Gass, I. Maclaren, M. Preuss, The microstructure and microtexture of zirconium oxide films studied by transmission electron backscatter diffraction and automated crystal orientation mapping with transmission electron microscopy, Acta Mater. 80 (2014) 159-171. doi:10.1016/j.actamat.2014.07.062.

[28] T. Tokarski, G. Cios, A. Kula, P. Bała, High quality transmission Kikuchi diffraction analysis of deformed alloys - Case study, Mater. Charact. 121 (2016) 231-236. doi:10.1016/j.matchar.2016.10.013.

[29] C. V. Thompson, Solid-State Dewetting of Thin Films, Annu. Rev. Mater. Res. 42 (2012) 399-434. doi:10.1146/annurev-matsci-070511-155048. 
[30] F. Leroy, Ł. Borowik, F. Cheynis, Y. Almadori, S. Curiotto, M. Trautmann, J.C. Barbé, P. Müller, How to control solid state dewetting: A short review, Surf. Sci. Rep. 71 (2016) 391409. doi:10.1016/j.surfrep.2016.03.002.

[31] G. Atiya, D. Chatain, V. Mikhelashvili, G. Eisenstein, W.D. Kaplan, The role of abnormal grain growth on solid-state dewetting kinetics, Acta Mater. 81 (2014) 304-314. doi:10.1016/j.actamat.2014.08.038.

[32] A. Kosinova, L. Klinger, O. Kovalenko, E. Rabkin, The role of grain boundary sliding in solidstate dewetting of thin polycrystalline films, Scr. Mater. 82 (2014) 33-36. doi:10.1016/j.scriptamat.2014.03.015.

[33] F. Ruffino, M.G. Grimaldi, Controlled dewetting as fabrication and patterning strategy for metal nanostructures, Phys. Status Solidi. 212 (2015) 1662-1684. doi:10.1002/pssa.201431755.

[34] F. Niekiel, S.M. Kraschewski, P. Schweizer, B. Butz, E. Spiecker, Texture evolution and microstructural changes during solid-state dewetting: A correlative study by complementary in situ TEM techniques, Acta Mater. 115 (2016) 230-241. doi:10.1016/j.actamat.2016.05.026.

[35] C.M. Müller, R. Spolenak, Microstructure evolution during dewetting in thin Au films, Acta Mater. 58 (2010) 6035-6045. doi:10.1016/j.actamat.2010.07.021.

[36] N. Hanief, M. Topić, C. Pineda-Vargas, Solid-state dewetting of continuous thin platinum coatings, in: Nucl. Instruments Methods Phys. Res. Sect. B Beam Interact. with Mater. Atoms, North-Holland, 2015: pp. 173-176. doi:10.1016/j.nimb.2015.06.030.

[37] J. Ye, D.J. Srolovitz, M.E. Coltrin, C.C. Mitchell, J. Eymery, Fabrication of ordered arrays of micro- and nanoscale features with control over their shape and size via templated solidstate dewetting, Sci. Rep. 5 (2015) 9823. doi:10.1038/srep09823.

[38] M. Kang, S.-G. Park, K.-H. Jeong, Repeated Solid-state Dewetting of Thin Gold Films for Nanogap-rich Plasmonic Nanoislands, Sci. Rep. 5 (2015) 14790. doi:10.1038/srep14790.

[39] C. Worsch, M. Kracker, W. Wisniewski, C. Rüssel, Optical properties of self assembled oriented island evolution of ultra-thin gold layers, Thin Solid Films. 520 (2012) 4941-4946. doi:10.1016/j.tsf.2012.03.016.

[40] M. Altomare, N.T. Nguyen, P. Schmuki, Templated dewetting: designing entirely selforganized platforms for photocatalysis, Chem. Sci. 7 (2016) 6865-6886. doi:10.1039/C6SC02555B.

[41] D. Wang, P. Schaaf, Solid-state dewetting for fabrication of metallic nanoparticles and influences of nanostructured substrates and dealloying, Phys. Status Solidi. 210 (2013) 1544-1551. doi:10.1002/pssa.201200895.

[42] C. Manuela Müller, R. Spolenak, Dewetting of Au and AuPt alloy films: A dewetting zone model, J. Appl. Phys. 113 (2013) 94301. doi:10.1063/1.4794028.

[43] P.D. Nsimama, A. Herz, D. Wang, P. Schaaf, Influence of the substrate on the morphological evolution of gold thin films during solid-state dewetting, Appl. Surf. Sci. 388 (2016) 475-482. doi:10.1016/j.apsusc.2015.11.185.

[44] F. Niekiel, P. Schweizer, S.M. Kraschewski, B. Butz, E. Spiecker, The process of solid-state dewetting of Au thin films studied by in situ scanning transmission electron microscopy, Acta Mater. 90 (2015) 118-132. doi:10.1016/j.actamat.2015.01.072. 
[45] P. Jacquet, R. Podor, J. Ravaux, J. Teisseire, I. Gozhyk, J. Jupille, R. Lazzari, Grain growth: The key to understand solid-state dewetting of silver thin films, Scr. Mater. 115 (2016) 128132. doi:10.1016/j.scriptamat.2016.01.005.

[46] S.A. Jang, H.J. Lee, C. V. Thompson, C.A. Ross, Y.J. Oh, Crystallographic analysis of the solid-state dewetting of polycrystalline gold film using automated indexing in a transmission electron microscope, APL Mater. 3 (2015) 126103. doi:10.1063/1.4937432.

[47] B.S. El-Dasher, S.G. Torres, Electron backscatter diffraction in low vacuum conditions, Electron Backscatter Diffr. Mater. Sci. (2009) 339-344. doi:10.1007/978-0-387-88136-2_25.

[48] C.C. Wong, H.I. Smith, C. V. Thompson, Surface-energy-driven secondary grain growth in thin Au films, Appl. Phys. Lett. 48 (1986) 335-337. doi:10.1063/1.96543.

[49] H.J. Frost, Microstructural evolution in thin films, Mater. Charact. 32 (1994) 257-273. doi:10.1016/1044-5803(94)90102-3.

[50] A. Winkelmann, G. Nolze, Analysis of Kikuchi band contrast reversal in electron backscatter diffraction patterns of silicon, Ultramicroscopy. 110 (2010) 190-194. doi:10.1016/j.ultramic.2009.11.008.

[51] F. Niekiel, S.M. Kraschewski, J. Mueller, B. Butz, E. Spiecker, Local temperature measurement in TEM by parallel beam electron diffraction, Ultramicroscopy. 176 (2017) 161-169. doi:10.1016/j.ultramic.2016.11.028.

[52] F. Niessen, A. Burrows, A.B. da S. Fanta, A systematic comparison of on-axis and off-axis transmission Kikuchi diffraction, Ultramicroscopy. (2017). doi:10.1016/J.ULTRAMIC.2017.12.017.

[53] W.H. Qi, M.P. Wang, Size and shape dependent melting temperature of metallic nanoparticles, Mater. Chem. Phys. 88 (2004) 280-284. doi:10.1016/J.MATCHEMPHYS.2004.04.026.

[54] Y.Z. Wang, M.G. Kong, Z.W. Liu, C.C. Lin, Y. Zeng, Effect of microscope parameter and specimen thickness of spatial resolution of transmission electron backscatter diffraction., $\mathrm{J}$. Microsc. 264 (2016) 34-40. doi:10.1111/jmi.12413.

[55] H. YUAN, E. BRODU, C. CHEN, E. BOUZY, J.-J. FUNDENBERGER, L.S. TOTH, On-axis versus off-axis Transmission Kikuchi Diffraction technique: application to the characterisation of severe plastic deformation-induced ultrafine-grained microstructures, $\mathrm{J}$. Microsc. 0 (2017) 1-11. doi:10.1111/jmi.12548.

[56] Sample Preparation - DENSsolutions, (n.d.). http://denssolutions.com/sample-preparation/ (accessed 30 November 2017). 